\title{
PERANAN SISTEM INFORMASI GEOGRAFI DALAM PENGELOLAAN SUMBER DAYA HUTAN DI INDONESIA
}

\author{
Oleb: \\ Subarto Widjojo \\ Sambiyo
}

.

\begin{abstract}
Exploitation of forest resources should be balanced by appropriate management in order to supply of the resources are not extinct. Resources management sot only need much time, cost, and workers, but difficult to get bomogeneity of the Lata as well.

Tbrough the developement of Geographic Information System (GIS) technology is expected that the forest resources management can be done easily.
\end{abstract}

\section{INTISARI}

Eksploitasi sumberdaya butan yang berlangsung secara cepat perlu diimbangi dengan pengelolaan yang cukup baik agar sumberdaya yang tersedia tidak punab. Pengelolaan sumberdaya yang dilakukan secara konvensional akan menyiLa waktu, biaya dan tenaga di samping sulit diperoleb keseragaman data.

Dengan dikembangkannya teknologi sistem informasi geografi (GIS/SIG) dibarapkan dapat membanlu pengelolaan sumberdaya butan yang ada yang akbirnya akan mempermudab pemanfaalan sumberdaya yang tersedia secara optimal.

\section{Pendahuluan}

Sumberdaya lahan yang tersedia di suatu wilayah perlu dikelola dengan baik agar dapat dimanfaatkan secara optimal di samping terjaga kelestariannya. Keadaan yang sering terjadi, manusia cenderung untuk memanfaatkan sumberdaya yang ada untuk kepentingannya tetapi kurang memperhatikan kelangsungan tersedianya sumberdaya tersebut.

Untuk optimalisasi pengelolaan sumberdaya hutan perlu keterpaduan antar sektor untuk menghilangkan gap dan overlaps dalam pengelolaannya. Teknologi Sistem Informasi Geografi (SIG/GIS) menawarkan kemampuannya untuk pengelolaan sumberdaya tersebut.

GIS telah terbukti mempunyai kegu. naan dalam memberi masukan untuk pengambilan keputusan dalam penge. lolaan sumberdaya lahan khususnya hutan seperti:

1. Pelaksanaan inventarisasi dan pengelolaan hutan secara digital dan periodik sehingga akan diperolch data yang up-to-date

2. Pengembangan pengelolaan data 
spasial dan kemampuan analisa (Ripple, Ed., 1987).

Dengan pertimbangan-pertimbangan tersebut di atas akan dibahas peranan GIS dalam Pengelolaan Sumberdaya hutan di Indonesia.

\section{Pengertian Sistem Informasi Geo- grafi (GIS/SIG)}

Menurut D.R. Fraser Taylor dalam bukunya Geographic Information Systems, the Microcomputer and Cartog. raphy, 1991, menyebutkan bahwa yang dimaksud GIS adalah,

a system for capturing, storing, checking, integrating, manipulat ing, analysing and displaying dala which are spalially refer. enced to the earth. (Taylor, D.R. Fraser, ed., 1991).

GIS sendiri terdiri atas empat subsistem yaitu, input data, manajemen data, manipulasi dan analisa data serta output data.

Input data GIS diperoleh atau diproses dari peta yang tersedia, tabel, foto udara, citra satelit, hasil survey lapangan dan lain. lain ke dalam bentuk yang dapat digunakan dalam GIS atau dalam bentuk digital.

Komponen manajemen data dari GIS termasuk beberapa fungsi penyimpanan spasial data dalam bentuk yang memungkinkan untuk dipanggil kembali secara cepat oleh users di samping memungkinkan untuk dilakukan koreksi database secara cepat dan akurat.

Fungsi manipulasi dan analisa data memungkinkan pengguna data untuk melakukan beberapa jenis kegiatan seperti merubah bentuk data, melakukan overlay, perhitungan aritmatik atau ge- neralisasi dan sebagainya.

Data output atau laporan mampu menyajikan sebagian atau semua database dan hasil manipulasi data dalam bentuk tabel, hard copy (peta) atau soft copy (file elcktronik). (Ripple, ed., 1987, Aronoff, 1989).

\section{Kemampuan GIS}

Pada periode yang silam inventarisasi sumberdaya lahan khususnya hutan telah banyak dilakukan baik secara manual maupun secara digital, tetapi keberadaan untuk proses analisa komponen belum nampak. Pengambilan keputusan untuk pengelolaan hutan memerlukan tidak hanya inventarisasi hutan pada masa sekarang, tetapi juga kemampuan untuk memprediksi inventarisasi pada saat yang akan datang. Untuk kepentingan tersebut diperlukan data yang tepat, akurat dan dalam format yang seragam. Fasilitas tersebut dimungkinkan dengan digunakannya GIS dalam pengelolaannya.

Dengan menggunakan GIS user dapat melakukan kegiatan-kegiatan dalam manipulasi dan analisa data seperti: merubah, menambah, menghapus atau memodifikasi data yang ada dan mengganti dengan data baru yang be. nar tanpa mengganggu struktur data lainnya. Lebih lanjut user juga akan mampu melakukan transformasi peta dengan merubah skala, projeksi, melakukan UNION, INTERSECTION antara dua peta atau lebih dan lain-lain untuk menghasilkan peta akhir yang akurat dan up-to-date.

Di samping itu peta yang dibuat secara digital akan lebih mudah digu. nakan oleh user karena ada beberapa keuntungan antara lain:

1. Data dapat dikelola dalam format 
rang kompak.

2 Dara dapat dikelola dengan biaya rang lebih rendah per unit data.

5. Data dapat dipanggil kembali dengan cepat.

4 Beberapa komputer memungkinkan user untuk melakukan manipulasi data termasuk transformasi, overlay dan manipulasi dalam database.

5 Data grafis (spasial) dan non grafis (non spasial) dapat dikelola secara bersama.

5. Analisa perubahan data untuk dua periode waktu atau lebih dapat disajikan secara lebih effisien.

- Beberapa data yang sulit disajikan secara manual dapat disajikan secara sederhana dan effisien seperti pembuatan peta tiga dimensi.

8. Ada tendensi untuk melakukan integrasi antara pengumpulan data, analisa spasial dan proses pembuatan keputusan

Di samping beberapa keuntungan ada beberapa kelemahan yang perlu diperhatikan adalah

1 Biaya dan masalah tcknis lainnya dalam hal konversi data manual ke digital.

2 Perlu biaya yang besar untuk mengelola data digital, seperti kom. puter, teknisi, pengelolaan perangkat lunak dan sebagainya.

3. Perlu biaya awal yang besar untuk implementasi sistem (Dangermond, 1984).

Walaupun ada kelemahan-kelemahannya, namun user cenderung menggunakan sistem informasi geografi dalam operasional kegiatannya, karena keuntungan lebih dominan.

Dalam bidang kehutanan GIS dapat digunakan untuk beberapa keperluan seperti perencanaan penebangan hutan, pelestarian habitat salwa langka, perencanaan route jalan, pengelolaan padang rumput, area rekreasi, suplai sumberdaya air, pengelolaan hutan itu sendiri dan lain sebagainya (Aronoff, 1989).

Dengan adanya GIS dimungkinkan untuk melakukan transformasi data spasial ke dalam beberapa bentuk output seperti peta, tabel, grafik, gambar, diagram dan lain-lain. Kegiatan tersebut akan memberi informasi lebih bagi pembuatan keputusan. Tanpa adanya kemampuan analisa data spasial dari inventarisasi hutan bahan pengambilan keputusan akan menjadi terbatas

Di Amerika Scrikat tcknologi GIS untuk pengelolaan hutan telah dite. rima lebih dari lima tahun yang lalu dan digunakan untuk mengclola jutaan hektar hutan di negara tersebut. Departemen Kehutanan Amerika Serikat merencanakan untuk membeli sekitar 3.000 workstation untuk digunakan di 123 Balai Kehutanan di negara terscbut sedang dana yang dianggarkan untuk kebutuhan implementasi dan operasional GIS dari tahun 1988 sampai dengan 1993 mencapai Rp. 335,2 milyard (Walker \& Miller, 1990).

Inventarisasi hutan adalah alat utama untuk pengelolaan produksi kayu di Amerika Serikat. Data inventarisasi hutan dilakukan dengan sehnik penginderaan jauh didukung dengan survey lapangan. Basis unit hutan adalah te- gakan hutan. Interpreter mengidentifikasi batas tegakan hutan dengan menggunakan foto udara skala besar yaitu skala 1:10.000 sampai 1:20.000. Informasi seperti komposisi species, umur, tinggi, struktur dan kondisi hu. tan didapatkan dari hasil interpretasi didukung data lapangan. Informasi tersebut dimasukkan ke dalam GIS. Data lain yang diperlukan database kehutan- 
an adalah peta tanah, jaring jalan, sistem drainase, batas administrasi, pemilikan lahan dan lain-lain. Informasi yang berhubungan dengan tegakan hutan seperti penebangan, regenerasi, pembangunan jalan atau kerusakan hutan dapat juga dimasukkan dalam GIS.

Inventarisasi hutan secara konvensional dapat dilakukan secara aktif dan inventarisasi hutan dapat dilakukan setiap tahun. Tetapi untuk melakukan up dating perlu waktu yang panjang dan penggambaran secara manual akan memerlukan waktu yang lebih panjang lagi (kira-kira 5 sampai 20 kali waktu yang diperlukan untuk inventarisasi). Selain itu instansi yang berbeda mempunyai kemungkinan menyajikan data dalam format yang berlainan. Hal lain yang mungkin terjadi pada saat dilakukan inventarisasi atau penggambaran, perubahan baru mungkin saja terjadi. Hal ini akan menyulitkan penyajian data secara benar dan up-to-date.

\section{Peranan GIS Dalam Pengelolaan Sumber Daya Hutan}

Rimbawan dan manager industri hasil hutan memerlukan sejumlah informasi untuk membuat keputusan mengenai operasionalisasi silvikultur dalam mengelola hutan. Kebijakan tersebut diperlukan untuk memenuhi kebutuhan produksi secara maksima! dari lahan dengan biaya seminimal mungkin. GIS adalah alat yang dapat digunakan bagi rimbawan untuk manipulasi dan analisa sejumlah besar dari informasi di bidang kehutanan.

Kenaikan permintaan akan produksi hasil hutan sejalan dengan penurunan sumberdaya hutan memerlukan pemikiran tentang perlunya pengelc laan lahan secara lebih intensif. Bebe rapa industri hasil hutan menggunaka GIS untuk mengelola inventarisasi hu tan dan tegakan lain secara besar-be saran karena informasi tersebut sang diperlukan untuk pengelolaan hutar Nilai sebenarnya dari penggunaan Gl antara lain adalah dapat diperoleh dat. secara akurat dan up-to-date.

Meskipun GIS cukup potensial, be berapa industri hasil hutan, terutam di Indonesia, belum menggunakan GI dalam operasional harian disebabka beberapa faktor, antara lain:

1. Perlu dana yang besar untuk inves tasi awal dan waktu yang cuku panjang untuk implementasi, dig tasi peta, dan pengembangan data base.

2. Kekurangan tenaga ahli untuk me milih perangkat keras dan perang kat lunak yang sesuai untuk mendu kung manajemen dan pengambila keputusan sesuai kebutuhan di b dang kehutanan.

3. Kurangnya waktu untuk mengelol dan tranfer data ke digital dalan jumlah besar.

4. Beberapa instansi mungkin belun mempunyai data dan informasi yan diperlukan untuk digunakan secar ekonomis dan optimal (Walker an Miller, 1990).

Meskipun ada beberapa kendala sc perti telah disebut pada alenia seb lumnya, keberadaan GIS dalam penge lolaan sumberdaya terutama huta adalah mutlak diperlukan. Invent: risasi hutan secara manual tidak aka pernah selesai. Konversi awal dari pei manual ke digital walau perlu waktu t: ma dan melelahkan tetapi dengan d perolehnya data digital up dating aka dapat dilakukan jauh lebih sederhana.

Selain hal tersebut, manipulasi, an: 
lisa dan overlay data secara digital akan lebih sederhana dan data untuk bahan pengambilan keputusan akan diperolch sccara lebih cepat dan akurat.

Hal lain yang berperanan penting dengan digunakannya GIS adalah untuk menghindari konflik pengusahaan, pemilikan dan penggunaan lahan khususnya di kawasan hutan

\section{Kesimpulan}

Dengan memperhatikan kelebihan dan kendala penggunaan GIS dalam pengelolaan sumberdaya lahan khususnya hutan secara riil dapat disimpulkan bahwa Gils perlu dikembang- kan untuk inventarisasi, up clating data, manipulasi dan analisa data kchutanan. Biaya yang relatif mahal akan dapat dihindari kalau dapat dipilih sistem dan penggunaan yang sesuai dengan kebutuhan.

Perlu disiapkan tenaga terampil siap pakai untuk optimalisasi peralatan yang tersedia dalam menunjang inventarisasi, analisa dan pengampilan keputusan dalam hal pengelolaan sumberdaya.

Dengan digunakannya GiS maka keseragaman dan updating data akan dapat dilakukan secara mudah, cepat, akurat dan up-to-date.

\section{REFERENSI}

Aronoff, Stan., Geographic Information Systems: A Management Perspective, (). tawa, Canada: WIDI, Publications, 1989.

Dangermound, Jack., A Classification of Software Components Commonly Used in Geographic Information Systems, in Basic Readings in Geographic Information Systems, Williamsville, NY: SPAD Systems, Ltd., 1984.

Ripple, William J. cd., Geographic Information Systems For Resources Management : A Compendium, Falls Church, Virginia: Amcrican Society for Photogrammetry and Remote Sensing and American Congress on Surveying and Mapping, 1986.

Taylor, D.R. Fraser, ed., Geographic Information systems, the inicrocomputer and cartography, Toronto, Canada: Pergamon Press, 1991.

Walker, Teri C., and Richard K. Miller, Geographics Information Systems, An Assessment of Technology, Applications and Products, Madison, ISA: SI:AI Technical Publications, 1990. 